Tohoku J. Exp. Med., 1992, 168, 211-222

\title{
Functional Role of Glycosphingolipids in Tumor Progression
}

\author{
Sen-ITIRoh Hakomori \\ The Biomembrane Institute and Department of \\ Pathobiology, University of Washington, Seattle, WA, USA
}

НакомовI, S. Functional Role of Glycosphingolipids in Tumor Progression. Tohoku J. Exp. Med., 1992, 168 (2), 211-222 - Molecular modeling of glycosphingolipids (GSLs), and their organization in membranes, suggest that GSL "patches" provide binding sites for interaction with ligands and adjacent cells, and that GSLs or their catabolites modulate transmembrane signaling. Aberrant GSL expression is a ubiquitous phenotype common to essentially all types of tumors, and leads to (i) formation of tumor-associated antigens defind by a large variety of monoclonal anti-bodies; (ii) aberrant adhesion favoring metastasis and invasiveness of tumor cells ; and (iii) aberrant catabolism leading to altered transmembrane signaling and loss of growth control. Classical immunotherapy is based on (i). New approaches termed "antiadhesion" and "anti-signaling" therapy, based on (ii) and (iii), are hereby proposed. —— antiadhesion therapy ; glycosphingolipids ; integrin family; anti-signaling therapy ; tumor-associated antigen

Essentially all human and animal cancers are characterized by aberrant synthesis and organization of glycosphingolipids (GSLs) expressed at the cell surface. These changes are defined by specific monoclonal antibodies (MAbs), and some of them have been proven to be useful in diagnosis, monitoring, and treatment of human cancers. Changes in expression of GSLs in tumors result from (i) precursor accumulation due to incomplete synthesis, (ii) activation of neosynthesis, or (iii) organizational changes in membrane leading to high density and high exposure of GSLs. Specific GSLs, or the same epitopes expressed on carbohydrate (CHO) chains of glycoproteins, function as adhesion molecules which can be recognized by (i) other GSLs, or (ii) lectins, particularly the selectin family. Thus, tumor-associated $\mathrm{CHO}$ antigens (TACAs) may mediate metastatic deposition and define the site of metastasis. TACAs themselves, or anti-TACA MAbs, may serve not only as classical immunological reagents, but also as "antiadhesion" reagents for prevention of tumor progression.

Some GSLs, particularly GM3 ganglioside and its derivatives, and derivatives of sphingosine (SPN), including $\mathrm{N}, \mathrm{N}$-dimethylsphingosine (DMS), have been shown to be essential modulators of transmembrane signaling via protein kinase $\mathrm{C}(\mathrm{PKC})$, epidermal growth factor receptor kinase (EGF-RK), and other "onco-

Address for reprints : 201 Elliott Ave W, Seattle, WA 98119, USA. 
protein" kinases. Aberrant functioning of transmembrane signaling mechanisms is believed to promote uncontrolled proliferation of tumor cells. Therefore, exogenous addition of GSL derivatives may correct uncontrolled growth of, and possibly induce differentiation of tumor cells. Trials of DMS and N, N, Ntrimethylsphingosine (TMS) for this purpose have been successful. Some other examples will be discussed below.

\section{Basic structure and bifunctional role of GSLs}

GSLs are ubiquitous membrane components of essentially all eukaryotic cells, and are abundant in plasma membranes. Although over 150 molecular species have been identified, they can be classified into four major groups based on core structure of carbohydrate chain: (i) ganglio-series (Gal $\beta 1 \rightarrow 3$ GalNAc $\beta 1 \rightarrow$ $3 \mathrm{Gal} \beta 1 \rightarrow 4 \mathrm{Glc} \beta 1 \rightarrow 1 \mathrm{Cer}$ ) ; (ii) globo-series (GalNAc $\beta 1 \rightarrow 3 \mathrm{Gal} \alpha 1 \rightarrow 4 \mathrm{Gal} \beta 1 \rightarrow$ $4 \mathrm{Glc} \beta 1 \rightarrow 1 \mathrm{Cer}$ ) ; (iii) lacto-series type 1 chain $(\mathrm{Gal} \beta 1 \rightarrow 3 \mathrm{GlcNAc} \beta 1 \rightarrow 3 \mathrm{Gal} \beta 1 \rightarrow$ $4 \mathrm{Glc} \beta 1 \rightarrow 1 \mathrm{Cer}$ ) ; and (iv) lacto-series type 2 chain (Gal $\beta 1 \rightarrow 4 \mathrm{GlcNAc} \beta 1 \rightarrow 3 \mathrm{Gal} \beta 1$ $\rightarrow 4 \mathrm{Glc} \beta 1 \rightarrow 1 \mathrm{Cer}$ ). Of these four groups, (i) and (ii) are believed to occur only as GSLs, whereas (iii) and (iv) occur not only as GSLs but also as peripheral regions of glycoprotein $\mathrm{CHO}$ chains.

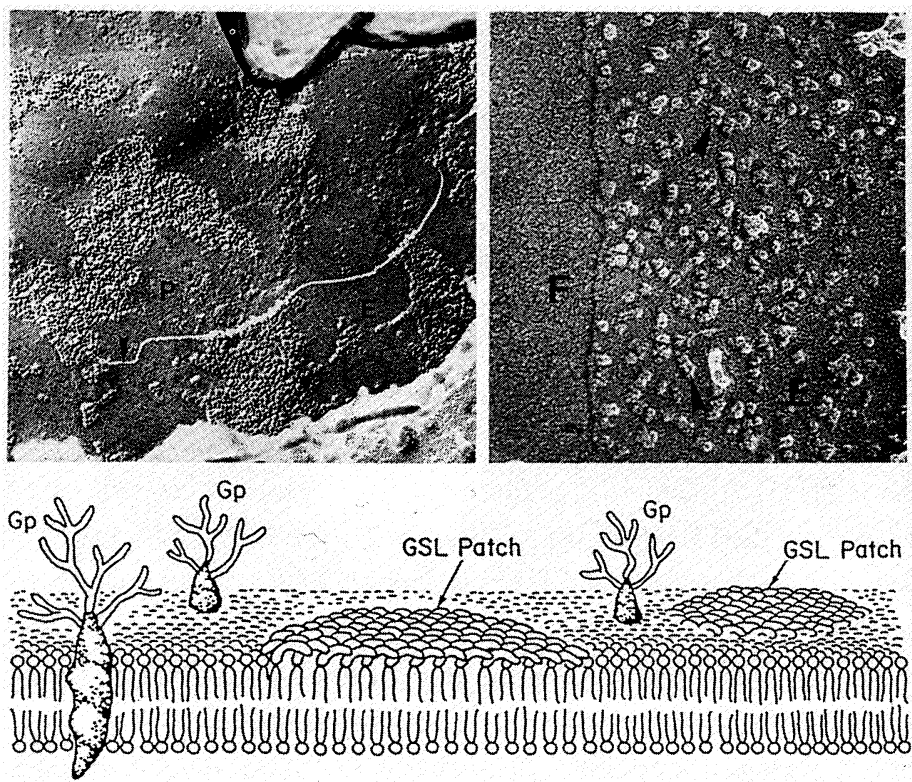

Fig. 1. Possible organization of GSLs at the cell surface.

Upper panel : distribution patterns of GSLs revealed by electron microscopy with freeze fracture technique using ferritin-labeled monovalent MAbs. Left: clustering of globoside on human erythrocytes. Right: clustering of Forssman antigen-containing GSLs. E, external surface; F, fractured surface (Tillack et al. 1983 ; Rock et al. 1990). Lower panel : conceptual model of GSL clustering to form membrane "patches." GP, glycoprotein. 
According to minimum energy conformational models based on hard sphere exoanomeric (HSEA) calculations, the axis of the CHO chain in GSLs is oriented perpendicular to the axis of the lipid moiety (ceramide) which is inserted in the lipid bilayer. The upper surface of the CHO chain in GSLs, which in most cases constitutes the hydrophobic domain and is surrounded by a hydrophilic area, is exposed at the cell surface (Hakomori 1986). This surface structure is the site to which various ligands complementary to GSLs are directed.

Electron micrographic studies based on freeze-etch technique using ferritinlabeled MAbs have revealed that GSLs are present at the external surface membrane, where they form large clusters rather than being distributed homogeneously in the lipid bilayer. Sometimes GSLs show a regular arrangement suggestive of a crystalline structure (Tillack et al. 1983; Rock et al. 1990, 1991). GSL clusters at the surface membrane may provide ideal loci for interaction with various ligands including animal cell lectins (e.g., selectins), antibodies, and complementary GSLs on neighboring cells (as discussed below). A conce-

TABLE 1. Six TACAs with extended type 1, type 2, or hybrid type 1/type 2 chains

\begin{tabular}{|c|c|}
\hline $\mathrm{Le}^{\mathrm{a}} / \mathrm{Le}^{\mathrm{a}}$ & $\begin{array}{rc}\text { Gal } \beta 3 \mathrm{GlcNAc} \beta 3 \mathrm{Gal} \beta 3 \mathrm{GlcNAc} \beta 3 \mathrm{Gal} \beta 4 \mathrm{Glc} \beta 1 \mathrm{Cer} \\
4 & 4 \\
\uparrow & \uparrow \\
\operatorname{Fuc} \alpha 1 & \operatorname{Fuc} \alpha 1\end{array}$ \\
\hline $\mathrm{Le}^{\mathrm{b}} / \mathrm{Le}^{\mathrm{a}}$ & \begin{tabular}{rcc}
\multicolumn{3}{c}{$\operatorname{Gal} \beta 3 \mathrm{GlcNAc} \beta 3 \mathrm{Gal} \beta 3 \mathrm{GlcNAc} \beta 1 \rightarrow \operatorname{al} \beta 4 \mathrm{Glc} \beta 1 \mathrm{Cer}$} \\
4 & 4 & 4 \\
Fuc $\alpha 1$ & $\operatorname{Fuc} \alpha 1$ & $\uparrow$
\end{tabular} \\
\hline $\mathrm{Le}^{\mathrm{a}} / \mathrm{Le}^{\mathrm{x}}$ & $\begin{array}{rc}\text { Gal } \beta 3 \mathrm{GlcNAc} \beta 3 \mathrm{Gal} \beta 4 \mathrm{GlcNAc} \beta 1 \rightarrow \operatorname{al} \beta 4 \mathrm{Glc} \beta 1 \mathrm{Cer} \\
4 & 3 \\
\uparrow & \uparrow \\
\operatorname{Fuc} \alpha 1 & \text { Fuc } \alpha 1\end{array}$ \\
\hline $\mathrm{Le}^{\mathrm{x}} / \mathrm{Le}^{\mathrm{x}}$ & $\begin{array}{cc}\text { Gal } \beta 4 \mathrm{GlcNAc} \beta 3 \mathrm{Gal} \beta 4 \mathrm{GlcNAc} \beta 1 \rightarrow \mathrm{al} \beta 4 \mathrm{Glc} \beta 1 \mathrm{Cer} \\
3 & 3 \\
\uparrow & \uparrow \\
\operatorname{Fuc} \alpha 1 & \operatorname{Fuc} \alpha 1\end{array}$ \\
\hline $\mathrm{Le}^{\mathrm{y}} / \mathrm{Le}^{\mathrm{x}}$ & \begin{tabular}{rcc}
\multicolumn{3}{c}{$\operatorname{Gal} \beta 4 \mathrm{GlcNAc} \beta 3 \mathrm{Gal} \beta 4 \mathrm{GlcNAc} \beta 1 \rightarrow \mathrm{al} \beta 4 \mathrm{Glc} \beta 1 \mathrm{Cer}$} \\
2 & 3 & 3 \\
Fuc $\alpha 1$ & $\operatorname{Fuc} \alpha 1$ & $\uparrow$
\end{tabular} \\
\hline $\mathrm{s}-\mathrm{Le}^{\mathrm{x}} / \mathrm{Le}^{\mathrm{x}}$ & $\begin{array}{rcc}\operatorname{Gal} \beta 4 \mathrm{GlcNAc} \beta 3 \mathrm{Gal} \beta 4 \mathrm{GlcNAc} \beta 3 \mathrm{Gal} \beta 4 \mathrm{Glc} \beta 1 \mathrm{Cer} \\
3 & 3 & 3 \\
\uparrow & \uparrow & \uparrow \\
\operatorname{NeuAc} \alpha 2 & \operatorname{Fuc} \alpha 1 & \operatorname{Fuc} \alpha 1\end{array}$ \\
\hline
\end{tabular}

$\mathrm{Le}^{\mathrm{a}} / \mathrm{Le}^{\mathrm{a}}, \mathrm{Le}^{\mathrm{b}} / \mathrm{Le}^{\mathrm{a}}$ : (Stroud et al. 1991; Watanabe et al. 1991)

$\mathrm{Le}^{\mathrm{a}} / \mathrm{Le}^{\mathrm{x}}$ : (Martensson et al. 1988)

$\mathrm{Le}^{\mathrm{x}} / \mathrm{Le}^{\mathrm{x}}, \mathrm{s}-\mathrm{Le}^{\mathrm{x}} / \mathrm{Le}^{\mathrm{x}}$ : (Fukushi et al. 1984a, b)

$\mathrm{Le}^{\mathrm{y}} / \mathrm{Le}^{\mathrm{x}}$ : (Kaizu et al. 1986) 
ptual model of GSL organization in membranes is illustrated in Fig. 1.

\section{GSLs as TACAs}

Dramatic changes of GSL composition associated with oncogenic transformation induced by tumor viruses, as observed in the author's laboratory in 1968-1970 (Hakomori and Murakami 1968; Hakomori et al. 1968, 1971), and subsequent related studies (Hakomori et al. 1967; Yang and Hakomori 1971; Sundsmo and Hakomori 1976; Rosenfelder et al. 1977) indicated that some GSLs are TACAs. After introduction of the MAb approach in tumor immunology, many GSLs and glycoprotein CHOs were conclusively shown to be TACAs. This area of study has been repeatedly reviewed (Hakomori and Kannagi 1983; Hakomori 1984, 1989). Here, simply for illustration, I will show five recently-characterized TACA structures based on extended type 1 chains, hybrid molecules of type 1 and type 2 chains, and extended type 2 chains with fucosyl and sialosyl substitutions (Table 1).

Some anti-TACA MAbs have obvious applications for suppression of tumor growth and monitoring of tumor progression, although extensive further studies are necessary before such applications become a practical clinical reality.

\section{GSLs and TACAs as adhesion molecules}

Recently, solid evidence for GSL/GSL interactions has been provided through several experimental approaches, e.g., specific interaction of GSL liposomes with GSL-coated plastic plates, auto- or hetero-aggregation of GSLcoated particles or liposomes, and affinity chromatography of GSL oligosaccharides on GSL-containing columns (Eggens et al. 1989 ; Kojima and Hakomori 1989, 1991a). Le $e^{x}$ interacts strongly with $\mathrm{Le}^{\mathrm{x}}$, and weakly with $\mathrm{Le}^{\mathrm{y}}$ or $n \mathrm{Lc}_{4}$. H/H, H/ $\mathrm{Le}^{\mathrm{y}}$, and N-acetyl-GM3/Gg3Cer also showed strong interaction (Fig. 2A, 2B). While the physiological significance (if any) of these various interactions remains to be determined, there are indications that $\mathrm{Le}^{\mathrm{x}} / \mathrm{Le}^{\mathrm{x}}$ interaction plays a key triggering role in compaction of morula, the first cell adhesion event occurring in ontogenesis of vertebrates (Eggens et al. 1989), and that $\mathrm{H} / \mathrm{Le}^{\mathrm{y}}$ interaction initiates implantation of the embryo in endometrium (Fenderson et al. 1991).

In other recent studies, cell adhesion mediated by GSL-GSL interaction was shown to be greatly enhanced (in terms of rapidity and intensity) when the cells express an integrin and the relevant adhesive protein is co-coated on plates with a certain GSL. For example, B16 melanoma cells (which express GM3) are known to adhere to LacCer-coated plates via GM3/LacCer interaction (Kojima and Hakomori 1991a). When plates were co-coated with LacCer plus fibronectin or laminin, rapidity and intensity of the adhesion were enhanced 5- to 10-fold (particularly at early stages of adhesion), suggesting the importance of cofunctioning of adhesion systems based on GSL-GSL and integrin-adhesive protein interactions. It is important to note that GSL-GSL interactions occur earlier 


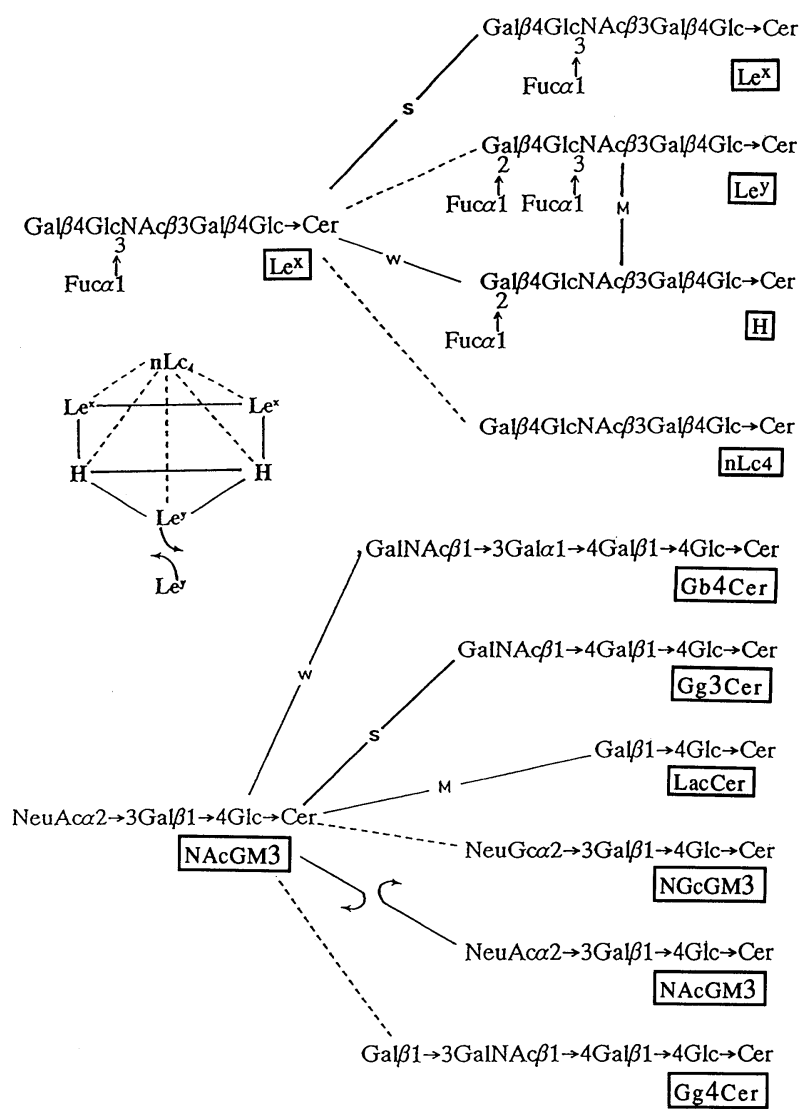

Fig. 2A. Interactions between complementary GSLs.

Chemical structure of various GSLs interacting with Le $\mathrm{e}^{\mathrm{x}}$ (upper) and NAcGM3 (lower). Solid line with $\mathrm{S}$ indicates strong interaction; with $\mathrm{M}$, medium interaction; with $\mathrm{W}$, weak interaction. Dotted line indicates no interaction. Two arrows indicate repellant (negative) interaction.

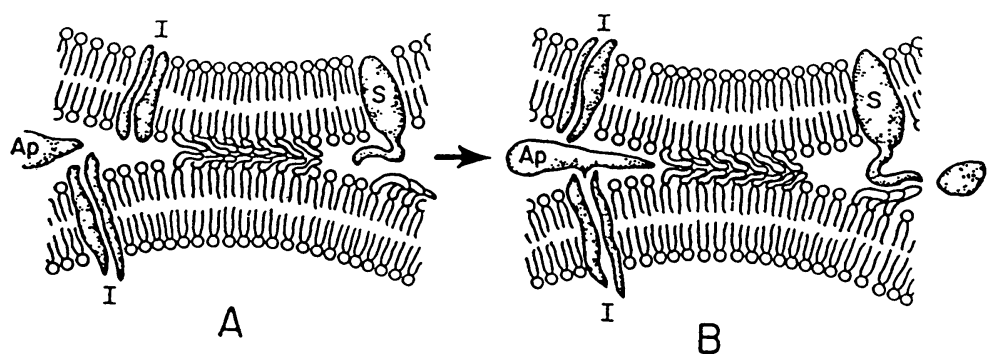

Fig. 2B. Interactions between complementary GSLs (continued).

GSL-GSL interactions may proceed through GSL' patches as shown in Fig. 1. $A$, at initial stage of interaction; $B$, at later stage of interaction involving adhesive protein (Ap), integrin receptor $(\mathrm{I})$ and selectin $(\mathrm{S})$. 

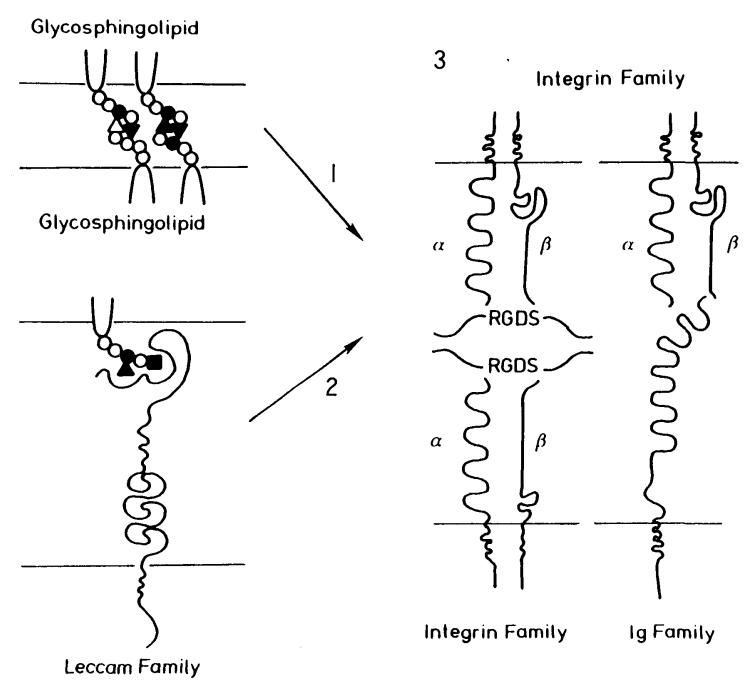

Fig. 3. Four types of cell adhesion systems.

1, GSL-GSL interaction. 2, CHO-lectin (including LECCAM). 3, integrinIg family-adhesive protein or Ig family-integrin.

than integrin interactions, whereas the latter are stronger than the former (Kojima and Hakomori 1991b).

Other recent studies reveal that a new class of adhesion molecules (selectins) are capable of recognizing cell surface GSLs, or the same epitopes present on glycoproteins. Selectins are normally not expressed, but become highly expressed upon stimulation of cells by specific physiological compounds. For example, ELAM-1 becomes expressed on endothelial cells (ECs) when they are stimulated by IL-1, TGF $\beta$, TNF $\alpha$, or bacterial lipopolysaccharides. GMP-140 (CD62, or PADGEM) becomes highly expressed on platelets or ECs when they are stimulated by thrombin, ADP, or TPA. The epitope recognized by both ELAM-1 and GMP-140 is now known to be sialosyl-Le ${ }^{\mathrm{x}}$ (Phillips et al. 1990 ; Polley et al. 1991), and ELAM-1 may recognize sialosyl-Le ${ }^{\text {a }}$ as well (Berg et al. 1991 ; Takada et al. 1991). Since platelets play a crucial role in defining the processes of hemostasis, inflammation, wound healing, and tumor cell metastasis, there has been much recent interest in the induction of expression of GMP-140 and ELAM1 , in terms of possible therapeutic applications. The four currently-recognized cell adhesion systems are summarized in Fig. 3.

Applications based on CHO-dependent adhesion for prevention of disease processes (anti-adhesion therapy)

Since GSLs are directly involved in crucial events of cell adhesion, i.e., GSL-GSL and GSL-selectin interactions, it seems likely that application of GSLs themselves, their oligosaccharide derivatives, or anti-GSL MAbs could inhibit the 


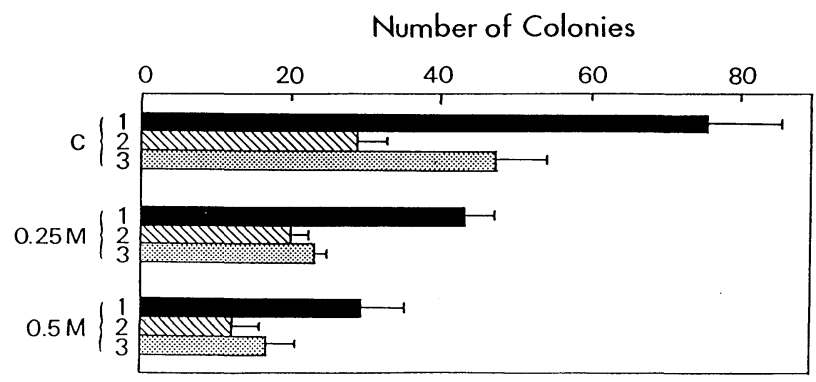

Fig. 4. Example of anti-adhesion treatment for prevention of B16/BL6 melanoma metastasis.

Effect on lung colonization potential by i.p. injection of methyl- $\beta$-lactoside and i.v. injection of BL6 cells. Upper group of three columns: control (injected PBS). Middle group : $100 \mu \mathrm{l}$ of $0.50 \mathrm{M}$ methyl- $\beta$-lactoside, i.p. injected. Lower group : $100 \mu 1$ of $0.50 \mathrm{M}$ methyl- $\beta$-lactoside, i.p. injected. Within each group of three, the top through bottom bars represent numbers of total colonies (solid bar), colonies with diameter $>1 \mathrm{~mm}$ (striped bar), and colonies with diameter $<1 \mathrm{~mm}$ (shaded bar), respectively.

cell adhesion processes involved in inflammation or tumor cell metastasis. MAbs against adhesion molecules such as integrins, or peptide sequences essential for cell adhesion (e.g., RGDS, YIGSR), have also been successfully applied for inhibition of metastasis (Humphries et al. 1986; Iwamoto et al. 1987; Saiki et al. 1989). Methyl- $\beta$-lactoside (but not methyl- $\beta$ - $\mathrm{N}$-acetyllactosaminide, $\mathrm{N}$-acetyllactosamine, or methyl- $\beta$-galactoside) has been shown to significantly inhibit lung metastasis of B16 melanoma cells. This was true not only when methyl- $\beta$ lactoside and B16 cells were intravenously co-injected, but also when they were injected by different routes (e.g., methyl- $\beta$-lactoside intraperitoneally, B16 cells intravenously) or at different times (Oguchi et al. 1990 ; Otsuji, E., Tashiro, K., Kojima, N., Hakomori, S. unpubl.) (Fig 4). This inhibitory effect was not due to blocking of galactose- or lactose-binding lectins claimed to be present on B16 cells (Raz and Lotan 1987), since MAbs against these lectins did not stain the B16 cells used in the experiments, nor block adhesion of B16 cells to ECs. The phenomenon seems to depend on GM3-LacCer interaction, i.e., GM3 highly expressed on B16 cells adheres to LacCer expressed on ECs. This adhesion is inhibited in the presence of methyl- $\beta$-lactoside, LacCer, GM3, or sialidase (Kojima, N., Tashiro, K., Sadahira, Y., Hakomori, S. unpubl.). Similar approaches using sialosyl-Le ${ }^{\mathrm{x}}$ or sialosyl-Le ${ }^{a}$ oligosaccharides and their derivatives for inhibition of tumor cell metastasis in humans are possible, since these CHO sequences are recognized by selectins and are therefore capable of blocking selectin binding to tumor cells.

\section{Regulation of cell proliferation and transmembrane signaling by GSLs and their derivatives}

Growth factor receptor-associated kinases, PKC, and the G-protein family 


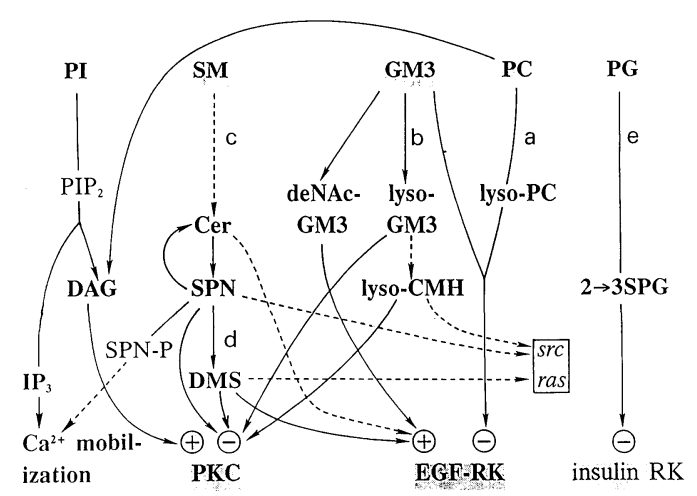

Fig. 5. Conceptual scheme for the cooperative modulatory effects of GSLs, phospholipids, and their metabolites on key regulators of cell proliferation. Membrane GSL $_{\mathrm{s}}$ (GM3, paragloboside [PG]), phospholipids (PC, SM, phosphatidylinositol $[\mathrm{PI}]$ ), and their derivatives (DAG, SPN, DMS, lyso-GM3, de-N-acetyl-GM3, $2 \rightarrow 3$ sialosylparagloboside [ $2 \rightarrow 3 \mathrm{SPG}$ ], ceramide [Cer]) function as modulators of PKC, EGF-RK, and insulin RK, some of them possibly affecting src and ras oncoproteins. Metabolic pathways (a), (b), (c), (d), and (e) are important in inhibition of EGF-RK, PK-C, and insulin RK ; therefore, factors (enzymes) involved in these pathways could be antioncogenic. In addition, the PI derivatives $\mathrm{PIP}_{2}$ (phosphatidylinositol 4, 5-bis-phosphate), and $\mathrm{IP}_{3}$ (inositol triphosphate), created by pathway (f), and SPN-P (SPN-1-phosphate), created by pathway (h), act to induce $\mathrm{Ca}^{2+}$ mobilization, and consequently to promote cell growth. Dashed lines indicate processes that consist of multiple steps. Lyso-CMH (psychosine) in the presence of GM3 inhibits src and ras-associated kinase activity, while SPN and DMS enhance this activity (Abdel-Ghany et al. 1992).

constitute the three major transmembrane signaling mechanisms which function in the majority of eukaryotic cells. The former two mechanisms are known to be modulated by gangliosides or their catabolites, particularly GM3, lyso-GM3, de-N-acetyl-GM3, SPN, and DMS (Bremer et al. 1984, 1986 ; Hanai et al. 1988; Igarashi et al. 1989, 1990). Insulin receptor kinase, which is regarded as an important regulator of cell growth, was specifically inhibited by sialosylparagloboside (Nojiri et al. 1991). The effects of various GSLs and phospholipids on transmembrane signaling mechanisms are summarized in Fig. 5.

Application of GSL and sphingolipid derivatives for control of tumor cell growth ("anti-signaling" therapy)

Based on the well-documented effects of various GSL and sphingolipid derivatives on key molecules involved in transmembrane signaling and cell growth regulation, we have tested some relatively simple compounds such as DMS and TMS for possible inhibitory effects on tumor growth and metastasis. Aberrant expression of $\mathrm{PKC}$ is a common feature of various tumor types, and $\mathrm{PKC}$ and receptor-associated kinases are assumed to play essential roles in tumor progres- 


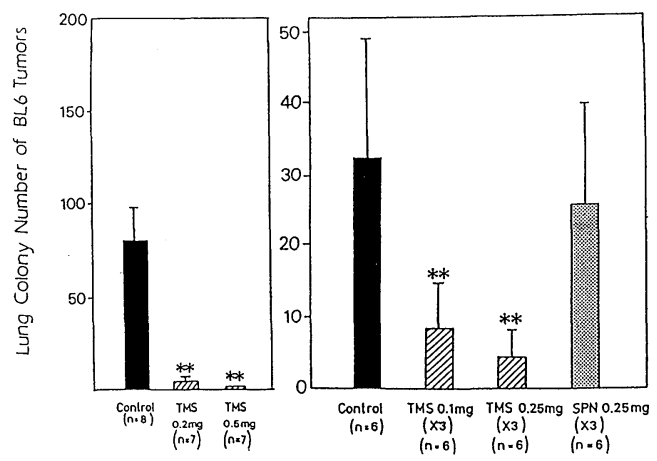

Fig. 6. Example of ortho-signaling treatment for prevention of B16/BL6 melanoma metastasis.

Effect of TMS on BL6 melanoma metastasis. Left panel, BL6 cells $\left(4 \times 10^{4}\right)$ and TMS were i.v. injected consecutively. One group $(n=7)$ was injected with $0.2 \mathrm{mg}$ TMS ; another group $(n=7)$ was injected with $0.5 \mathrm{mg}$ TMS. Right panel, effect of TMS and SPN on spontaneous metastasis. BL6 tumors were grown subcutaneously in the footpad and TMS was injected at $0.1 \mathrm{mg}$ $(n=6)$ or $0.25 \mathrm{mg}(n=6)$. Subsequently the primary tumor was resected, and later lung colonies were counted.

sion. In our recent studies, DMS and TMS were found to exert much stronger inhibitory effects (compared to previously tested reagents such as SPN, dibutyrylcAMP, and 8-chloro-cAMP) on in vitro and in vivo growth of a variety of human cancer cell lines. TMS was also found to be a strong inhibitor of tumor cellinduced platelet aggregation and B16 melanoma cell lung metastasis (Fig. 6). Results of these studies suggest that these compounds or their analogues, by blocking transmembrane signaling, could be useful inhibitors of tumor growth and metastasis. This "anti-signaling" approach is in obvious contrast to currently used approaches aimed at blocking of protein or nucleic acid synthesis, which involve reagents that are generally toxic and/or non-specific.

\section{Acknowledgments}

This study was supported by National Cancer Institute Outstanding Investigator Grant CA42505 (to S.H.) and funds from The Biomembrane Institute, in part under a research contract with Otsuka Pharmaceutical Co. The manuscript was edited and prepared by Dr. Stephen Anderson.

\section{References}

1) Abdel-Ghany M., Osusky M., Igarashi Y., Hakomori S., Shalloway D. and Racker E. (1992) Substrate-specific modulation of Src-mediated phosphorylation of Ras and caseins by sphingosine and other substrate modulators. Biochim. Biophys. Acta, 1137, 349-355.

2) Berg, E.L., Robinson, M.K., Mansson, O., Butcher, E.C. \& Magnani, J.L. (1991) A carbohydrate domain common to both sialyl $\mathrm{Le}^{\mathrm{a}}$ and sialyl $\mathrm{Le}^{\mathrm{x}}$ is recognized by the 
endothelial cell leukocyte adhesion molecule ELAM-1. J. Biol. Chem., 266, 1486914872.

3) Bremer, E., Hakomori, S., Bowen-Pope, D.F., Reaines, E. \& Ross, R. (1984) Ganglioside-mediated modulation of cell growth, growth factor binding, and receptor phosphorylation. J. Biol. Chem., 259, 6818-6825.

4) Bremer, E., Schlessinger, J. \& Hakomori, S. (1986) Ganglioside-mediated modulation of cell growth: Specific effects of $\mathrm{GM}_{3}$ on tyrosine phosphorylation of the epidermal growth factor receptor. J. Biol. Chem., 261, 2434-2440.

5) Eggens, I., Fenderson, B.A., Toyokuni, T., Dean, B., Stroud, M.R. \& Hakomori, S. (1989) Specific interaction between $\mathrm{Le}^{\mathrm{x}}$ and $\mathrm{Le}^{\mathrm{x}}$ deteminants : A possible basis for cell recognition in preimplantation embryos and in embryonal carcinoma cells. $J$. Biol. Chem., 264, 9476-9484.

6) Fenderson, B.A., Kojima, N., Stroud, M.R., Zhu, Z. \& Hakomori, S. (1991) Specific interaction between $\mathrm{Le}^{\mathrm{y}}$ and $\mathrm{H}$ as a possible basis for trophectoderm-endometrium recognition during implantation [Abstract 8.5]. Glycoconjugate J., 8, 179.

7) Fukushi, Y., Hakomori, S., Nudelman, E. \& Cochran, N. (1984a) Novel fucolipids accumulating in human adenocarcinoma: II. Selective isolation of hybridoma antibodies that differentially recognize mono-, di-, and trifucosylated type 2 chain. $J$. Biol. Chem., 259, 4681-4685.

8) Fukushi, Y., Nudelman, E., Levery, S.B., Rauvala, H. \& Hakomori, S. (1984b) Novel fucolipids accumulating in human cancer : III. A hybridoma antibody (FH6) defining a human cancer-associated difucoganglioside ( $\mathrm{VI}^{3} \mathrm{NeuAcV}{ }^{3} \mathrm{III}^{3} \mathrm{Fuc}_{2} \mathrm{nLc}_{6}$ ). J. Biol. Chem., 259, 10511-10517.

9) Hakomori, S. (1984) Tumor associated carbohydrate antigens. Ann. Rev. Immunol., 2, 103-126.

10) Hakomori, S. (1986) Tumor-associated glycolipid antigens, their metabolism and organization. Chem. Phys. Lipids, 42, 209-233.

11) Hakomori, S. (1989) Aberrant glycosylation in tumors and tumor-associated carbohydrate antigens. Adv. Cancer Res., 52, 257-331.

12) Hakomori, S. \& Murakami, W.T. (1968) Glycolipids of hamster fibroblasts and derived malignant-transformed cell lines. Proc. Natl. Acad. Sci. USA, 59, 254-261.

13) Hakomori, S. \& Kannagi, R. (1983) Glycosphingolipids as tumor-associated and differentiation markers. J. Natl. Cancer Inst., 71, 231-251.

14) Hakomori, S., Koscielak, J., Bloch, K.J. \& Jeanloz, R.W. (1967) Immunologic relationship between blood group substances and a fucose-containing glycolipid of human adenocarcinoma. J. Immunol., 98, 31-38.

15) Hakomori, S., Teather, C. \& Andrews, H. (1968) Organizational difference of cell surface "hematoside" in normal and virally transformed cells. Biochem. Biophys. Res. Commun., 33, 563-568.

16) Hakomori, S., Saito, T. \& Vogt, P.K. (1971) Transformation by Rous sarcoma virus : Effects on cellular glycolipids. Virology, 44, 609-621.

17) Hanai, N., Dohi, T., Nores, G.A. \& Hakomori, S. (1988) A novel ganglioside, de- $N$ acetyl-GM $\mathrm{GM}_{3}\left(\mathrm{II}^{3} \mathrm{NeuNH}_{2} \mathrm{LacCer}\right)$, acting as a strong promoter for epidermal growth factor receptor kinase and as a stimulator for cell growth. J. Biol. Chem., 263, 62966301.

18) Humphries, M.J., Olden, K. \& Yamada, K.M. (1986) A synthetic peptide from fibronectin inhibits experimental metastasis of murine melanoma cells. Science, 233, 467-470.

19) Igarashi, Y., Hakomori, S., Toyokuni, T., Dean, B., Fujita, S., Sugimoto, M., Ogawa, T., El-Ghendy, K. \& Racker, E. (1989) Effect of chemically well-defined sphingosine and its $N$-methyl derivatives on protein kinase $\mathrm{C}$ and src kinase activities. Biochemistry, 28, 6796-6800.

20) Igarashi, Y., Kitamura, K., Toyokuni, T., Dean, B., Fenderson, B.A., Ogawa, T. \& 
Hakomori, S. (1990) A specific enhancing effect of $N, N$-dimethylsphingosine on epidermal growth factor receptor autophosphorylation: Demonstration of its endogenous occurrence (and the virtual absence of unsubstituted sphingosine) in human epidermoid carcinoma A431 cells. J. Biol. Chem., 265, 5385-5389.

21) Iwamoto, Y., Robey, F.A., Graf, J., Sasaki, M., Kleinman, H.K., Yamada, Y. \& Martin, G.R. (1987) YIGSR, a synthetic laminin pentapeptide, inhibits experimental metastasis formation. Science, 238, 1132-1134.

22) Kaizu, T., Levery, S.B., Nudelman, E., Stenkamp, R.E. \& Hakomori, S. (1986) Novel fucolipids of human adenocarcinoma: VI. Monoclonal antibody specific for trifucosyl $\mathrm{Le}^{y}\left(\mathrm{III}^{3} \mathrm{FucV}^{3} \mathrm{FucVI}^{2} \mathrm{FucnLc}_{6}\right)$, and a possible three-dimensional epitope structure. J. Biol. Chem., 261, 11254-11258.

23) Kojima, N. \& Hakomori, S. (1989) Specific interaction between gangliotriaosylceramide (Gg3) and sialosyllactosylceramide (GM3) as a basis for specific cellular recognition between lymphoma and melanoma cells. J. Biol. Chem., 264, 20159-20162.

24) Kojima, N. \& Hakomori, S. (1991a) Cell adhesion, spreading, and motility of $\mathrm{G}_{\mathrm{M} 3}$-expressing cells based on glycolipid-glycolipid interaction. J. Biol. Chem., 266, $17552-17558$.

25) Kojima, N. \& Hakomori, S. (1991b) Synergistic effect of two cell recognition systems : Glycosphingolipid-glycosphingolipid interaction and integrin receptor interaction with pericellular matrix protein. Glycobiology, 1, 623-630.

26) Martensson, S., Due, C., Pahlsson, P., Nilsson, B., Eriksson, H., Zopf, D., Olsson, L. \& Lundblad, A. (1988) A carbohydrate epitope associated with human squamous lung cancer. Cancer Res., 48, 2125-2131.

27) Nojiri, H., Stroud, M.R. \& Hakomori, S. (1991) A specific type of ganglioside as a modulator of insulin-dependent cell growth and insulin receptor tyrosine kinase activity : Possible association of ganglioside-induced inhibition of insulin receptor function and monocytic differentiation induction in HL60 cells. J. Biol. Chem., 266, 4531-4537.

28) Oguchi, H., Toyokuni, T., Dean, B., Ito, H., Otsuji, E., Jones, V.L., Sadozai, K.K. \& Hakomori, S. (1990) Effect of lactose derivatives on metastatic potential of B16 melanoma cells. Cancer Commun., 2, 311-316.

29) Phillips, M.L., Nudelman, E., Gaeta, F.C.A., Perez, M., Singhal, A.K., Hakomori, S. \& Paulson, J.C. (1990) ELAM-1 mediates cell adhesion by recognition of a carbohydrate ligand, sialyl-Le ${ }^{\mathrm{x}}$. Science, 250, 1130-1132.

30) Polley, M.J., Phillips, M.L., Wayner, E.A., Nudelman, E., Singhal, A.K., Hakomori, S. \& Paulson, J.C. (1991) CD62 and endothelial cell-leukocyte adhesion molecule 1 (ELAM-1) recognize the same carbohydrate ligand, sialyl-Lewis x. Proc. Natl. Acad. Sci. USA, 88, 6224-6228.

31) Raz, A. \& Lotan, R. (1987) Endogenous galactoside-binding lectins: A new class of functional tumor cell surface molecules related to metastasis. Cancer Metast. Rev., 6, 433-452.

32) Rock, P., Allietta, M., Young, W.W., Jr., Thompson, T.E. \& Tillack, T.W. (1990) Organization of glycosphingolipids in phosphatidylcholine bilayers : Use of antibody molecules and Fab fragments as morphologic markers. Biochemistry, 29, 8484-8490.

33) Rock, P., Allietta, M., Young, W.W., Jr., Thompson, T.E. \& Tillack, T.W. (1991) Ganglioside $\mathrm{G}_{\mathrm{M} 1}$ and asialo- $\mathrm{G}_{\mathrm{M} 1}$ at low concentration are preferentially incorporated into the gel phase in two-component, two-phase phosphatidylcholine bilayers. Biochemistry, 30, 19-25.

34) Rosenfelder, G., Young, W.W., Jr. \& Hakomori, S. (1977) Association of the glycolipid pattern with antigenic alterations in mouse fibroblasts transformed by murine sarcoma virus. Cancer Res., 37, 1333-1339.

35) Saiki, I., Iida, J., Murata, J., Ogawa, R., Nishi, N., Sugimura, K., Tokura, S. \& Azuma, I. (1989) Inhibition of the metastasis of murine malignant melanoma by synthetic 
polymeric peptides containing core sequences of cell-adhesive molecules. Cancer Res., 49, 3815-3822.

36) Stroud, M.R., Levery, S.B., Nudelman, E.D., Salyan, M.E.K., Towell, J.A., Roberts, C.E., Watanabe, M. \& Hakomori, S. (1991) Extended type 1 chain glycosphingolipids : Dimeric $\mathrm{Le}^{\mathrm{a}}\left(\mathrm{III}^{4} \mathrm{~V}^{4} \mathrm{Fuc}_{2} \mathrm{Lc}_{6}\right)$ as human tumor-associated antigen. J. Biol. Chem., 266, 8439-8446.

37) Sundsmo, J. \& Hakomori, S. (1976) Lacto-N-neotetraosylceramide ("paragloboside") as a possible tumor-associated surface antigen of hamster NILpy tumor. Biochem. Biophys. Res. Commun., 68, 799-806.

38) Takada, A., Ohmori, K., Takahashi, N., Tsuyuoka, K., Yago, A., Zenita, K., Hasegawa, A. \& Kannagi, R. Adhesion of human cancer cells to vascular endothelium mediated by a carbohydrate antigen, sialyl Lewis A. Biochem. Biophys. Res. Commun., 179, 713-719.

39) Tillack, T.W., Allietta, M., Moran, R.E. \& Young, W.W., Jr. (1983) Localization of golboside and Forssman glycolipids on erythrocyte membranes. Biochim. Biophys. Acta, 733, 15-24.

40) Watanabe, M., Ohishi, T., Kuzuoka, M., Nudelman, E.D., Stroud, M.R., Kubota, T., Kodaira, S., Abe, O., Hirohashi, S., Shimosato, Y. \& Hakomori, S. (1991) In vitro and in vivo antitumor effects of murine monoclonal antibody NCC-ST-421 reacting with dimeric $\mathrm{Le}^{\mathrm{a}}\left(\mathrm{Le}^{\mathrm{a}} / \mathrm{Le}^{\mathrm{a}}\right)$ epitope. Cancer Res., 51, 2199-2204.

41) Yang, H.-J. \& Hakomori, S. (1971) A sphingolipid having a novel type of ceramide and lacto- $N$-fucopentaose III. J. Biol. Chem., 246, 1192-1200. 